\title{
Why dieters fail: Testing the goal conflict model of eating
}

\author{
Wolfgang Stroebe ${ }^{\mathrm{a}, *}$, Wendy Mensink ${ }^{\mathrm{a}}$, Henk Aarts ${ }^{\mathrm{a}}$, Henk Schut ${ }^{\mathrm{a}}$, Arie W. Kruglanski ${ }^{\mathrm{b}}$ \\ ${ }^{a}$ Department of Social and Organizational Psychology, Utrecht University, P.O. Box 80.140, 3508 TC Utrecht, The Netherlands \\ b Department of Psychology, University of Maryland, College Park, MD 20742, USA
}

Received 15 March 2006; revised 16 January 2007

Available online 30 January 2007

Communicated by Hart Blanton

\begin{abstract}
A new theory of eating regulation is presented to account for the over-responsiveness of restrained eaters to external food-relevant cues. According to this theory, the food intake of restrained eaters is characterized by a conflict between two chronically accessible incentives or goals: eating enjoyment and weight control. Their difficulty in weight control is due to their behavioral sensitivity to eating enjoyment and its incompatibility with the eating control goal. Accordingly, exposure to food-relevant stimuli primes the goal of eating enjoyment in restrained (but not unrestrained) eaters, resulting in an inhibition of weight control thoughts. Three studies are reported that support these assumptions. Study 1 demonstrates a substantial relation between Eating Restraint and measures of ambivalence towards eating. Studies 2 and 3 show that priming eating enjoyment decreases the accessibility of eating control concepts. The results are discussed in the context of current research on the psychology of obesity and restrained eating.
\end{abstract}

(C) 2007 Elsevier Inc. All rights reserved.

Keywords: Restrained eating; Dieting; Obesity; Priming; Goal conflict

There has been a dramatic increase in the prevalence of obesity in Western industrialized countries. For example, in the USA obesity rates have doubled and in Great Britain even tripled during the period from 1980 to 2000. These steep increases are a matter of grave concern, because obesity is associated with an increased risk of mortality and morbidity (Stroebe, 2000; World Health Organization, 2000). Genetic factors contribute to the development of obesity and some individuals are more at risk to gain weight than others at the same level of energy surplus (for a review, see Bouchard, Pérusse, Rice, \& Rao, 1998). However, since it is unlikely that the genetic make-up of the US or British population has changed substantially during the last decades, the rapid increases in obesity must have been due to a combination of environmental and behavioral changes. Thus, ultimately individuals become obese because they eat too much, particularly too much fat food, and exercise too little.

\footnotetext{
${ }^{*}$ Corresponding author.

E-mail address: W.Stroebe@fss.uu.nl (W. Stroebe).
}

But why do some individuals have a tendency to overeat? This is the central question to be addressed in this article. In trying to answer this question, we will first review the classic theories of eating and then present a new theory, the Goal Conflict Model of Eating. The main section of this article will describe empirical studies that have been conducted to test the cognitive processes that form the backbone of the goal conflict model.

\section{Classic theories of the regulation of eating}

The classic theories of the regulation of eating assume that obese and normal weight individuals differ in the way in which they regulate their food intake. This assumption has originally been suggested by the psychiatrist Hilde Bruch (e.g., 1961, 1974) who concluded from clinical observations of obese patients that these individuals were unable to differentiate sensations of hunger from other states of bodily arousal. Schachter, Goldman, and Gordon, 1968 found experimental support only for the assumption that eating behavior of obese respondents was not regulated 
by internal cues of hunger or satiation, but not for the second and more central assumption that eating behavior of obese individuals is triggered by emotional arousal. This led Schachter (1971) to propose that, in contrast to normal weight individuals, whose eating was regulated by internal hunger and satiety cues, the eating behavior of obese individuals was triggered by external, food-relevant, cues such as the time of day (e.g., dinner time) or the sight and smell of tasty food. Schachter and his colleagues (1971; Goldman, Jaffa and Schachter, 1968; Nisbett, 1968; Schachter et al., 1968; Schachter and Gross, 1968) conducted a series of innovative studies in which they tested this assumption. However, after initial enthusiasm, Schachter's theory was increasingly criticized because effects were weak and findings could not always be replicated (Rodin, 1981).

A potential explanation why tests of the externality assumption that compared obese to normal weight individuals may often have yielded weak effects was offered by Herman, Polivy and their colleagues with the construct of "restrained eating" (e.g., Herman \& Mack, 1975; Herman \& Polivy, 1984). Herman, Polivy and their colleagues (e.g., Herman \& Mack, 1975; Herman \& Polivy, 1984) argued that obese individuals frequently tried to diet in an attempt to conform to social prescriptions regarding body weight. When restrained individuals force themselves to ignore or override internal demands in their attempt to reduce their food intake, insensitivity to internal hunger cues and an over-reliance on external cues is likely to develop. Although overweight is one of the determinants of dietary restraint, the fact that many normal weight individuals are also restrained eaters could explain why the relationship between externality and overweight is weak.

Herman and Mack (1975) developed the Restraint Scale to assess the degree of self-imposed restriction of food intake and weight fluctuation. The revised version of this scale consists of a 10 item questionnaire with two subscales, measuring Weight Fluctuations and Concern for Dieting (Herman \& Polivy, 1980). Eating restraint correlates positively with both BMI and percentage of overweight individuals (e.g., Ruderman, 1986). In a sample of female students at Utrecht University we found a correlation of .42 between BMI and restrained eating (Mensink, Stroebe, \& Schut, 2001). The percentage of restrained eaters among the 20 individuals who were obese was $85 \%$.

Herman and Polivy (1984) integrated the construct of restrained eating into their Boundary Model of Eating Behavior, a theory which still dominates research on the cognitive regulation of eating. They proposed that biological pressures work to maintain food intake within a certain range (zone of biological indifference) between a hunger and a satiety boundary. Whereas with unrestrained eaters eating is regulated automatically within this range by internal hunger and satiety signals, restrained eaters are assumed to control their eating cognitively by imposing a diet-boundary that consists of a set of rules to limit food intake in order to maintain or achieve a desirable weight. Furthermore, due to their frequent dieting and overeating, restrained eaters are assumed to have become less sensitive to bodily hunger and satiation signals.

The cognitive regulation of eating behavior is a controlled process, that requires cognitive resources. If restrained eaters are able and motivated to concentrate on the regulation of their eating, they are quite capable to keep to their diet rules. However, if their motivation or ability to regulate their eating is impaired, overeating will occur. The boundary model suggests two classes of variables that can impair the regulation of eating in restrained eaters and induce overeating, namely the experience of strong emotions, and a previous violation of the diet boundary. There has been some empirical support for both the emotion hypothesis (e.g., Baucom \& Aiken, 1981; Frost, Goolkasian, Ely, \& Blanchard, 1982; Heatherton, Herman, \& Polivy, 1991; Heatherton, Striepe, \& Wittenberg, 1998; Herman, Polivy, Lank, \& Heatherton, 1987; Polivy, Herman, \& McFarlane, 1994) and the assumption that dietary violations induce overeating (e.g., Herman \& Mack, 1975; Herman, Polivy, \& Esses, 1987; Hibscher \& Herman, 1977). However, there is also evidence that exposure to palatable food tempts restrained eaters into overeating (Fedoroff, Polivy, \& Herman, 1997, 2003; Jansen \& van den Hout, 1991). For example, Jansen and van den Hout (1991) found that restrained eaters, who had been exposed to the smell of cakes, smarties and licorice before they were allowed to eat as much as they wanted of these delicacies, ate significantly more than restrained eaters, who had not been exposed to these smells. In contrast, exposure to food smells had no significant impact on consumption of unrestrained eaters. Similarly, Fedoroff and colleagues (1997, 2003) who exposed their respondents to the smell of pizza before they had to rate the taste of four freshly baked individual pizzas, found that the smell of pizza increased pizza consumption among restrained but not of unrestrained eaters.

Why should restrained eaters be tempted into eating by the sight and smell of palatable food? The (presumed) insensitivity of obese and other restrained eaters to internal cues does not really explain why these individuals should be more responsive to external (food) cues. To regulate their eating, they will have to rely more on calorie counting instead of internal hunger and satiety cues. But why should they be more tempted than unrestrained eaters by the sight of palatable food items, or the taste or smell of food, given that they often yield to this temptation? Nisbett (1972) had suggested differences in hunger feelings as a plausible explanation for this relationship. He had argued that "many obese individuals are actually in a chronic state of energy deficit and are genuinely hungry, perhaps because they attempt to hold their weight below its biologically dictated 'set point"' '(1972, p. 433). However, Herman and Polivy (1984) ruled out this explanation, when they argued that restrained individuals had become less able to recognize such signals. Since in our own studies (e.g., Papies, Stroebe, \& Aarts, 2007) we found restraint-scores to be uncorrelated with ratings of hunger, Herman and Polivy 
(1984) were probably correct in rejecting differences in hunger state as explanatory concept.

Then why do restrained eaters find it so difficult to disregard tempting food cues and to resist the temptation to consume palatable food? A number of theorists have suggested that the primary stimulus for eating is the positive-incentive value of food (e.g., Bolles, 1990; Pinel, Assanand, \& Lehman, 2000). According to this perspective people are drawn to eat by the anticipated pleasure of eating (i.e., positive incentive value) rather than a decline in their energy resources. However, the boundary model does not consider the anticipated pleasure of eating as important for the regulation of eating. We therefore developed the Goal Conflict Model of Eating (Stroebe, 2002) to acknowledge the important role of the anticipated pleasure of eating or eating enjoyment in eating regulation.

\section{The goal conflict model of eating}

According to the Goal Conflict Model of Eating, the eating behavior of restrained eaters is dominated by a conflict between two incompatible incentives or goals, namely the goal of eating enjoyment and the goal of weight control (Stroebe, 2002). Goals are mentally represented as desirable future states that the individual wants to attain (Aarts \& Dijksterhuis, 2000; Kruglanski, 1996; Shah \& Kruglanski, 2002; Shah, Friedman, \& Kruglanski, 2002). Restrained eaters are chronic dieters who want to reduce or at least maintain their present weight. At the same time, palatable food has a strong positive incentive value for them (e.g., Fedoroff et al., 1997). Thus, eating palatable food is a highly desirable end-state for restrained eaters. Therefore, in order to succeed in their pursuit of the weight control goal, they normally shield it by inhibiting thoughts about eating palatable food.

Unfortunately, our environment is rich in stimuli symbolizing or signaling palatable food and restrained eaters are very sensitive to such stimulation. To the extent that the stimulus context increases the accessibility of the goal of enjoying palatable food, the goal of eating enjoyment might interfere with the goal of weight control by pulling away from its limited regulatory resources (Shah \& Kruglanski, 2002). Since the goal of enjoying palatable food is incompatible with the goal of eating control, which has high chronic accessibility, continued exposure to palatable food primes the goal of eating enjoyment and results in inhibited access to the mental representation of the eating control goal (Shah et al., 2002). In other words, because it interferes with the selection and subsequent production of eating enjoyment goal-responses, the accessible goal of eating control is inhibited, rendering the goal of eating enjoyment more focal (see e.g., Anderson \& Spellman, 1995; Norman \& Shallice, 1986; for a discussion of these topics). Importantly, this inhibition process can occur outside conscious awareness (e.g., Bodenhausen \& Macrae, 1998; Shah et al., 2002).
Why do palatable food items have a more positive incentive value for restrained than for unrestrained eaters? One explanation, and one that appeared of obvious validity to us (e.g., Stroebe, 2000), was in terms of differences in attitudes. It would seem plausible that, compared to unrestrained eaters, restrained eaters hold more positive attitudes towards palatable food. However, research assessing attitudes towards palatable food using explicit (Mensink, 2005) as well as implicit measures (e.g., EAST: Roefs, Herman, MacLead, Smulders, \& Jansen, 2005; affective priming: Mensink, 2005; Roefs et al., 2005) found no support for this assumption. Unrestrained eaters liked palatable food as much as did restrained eaters. Thus, the difficulty restrained eaters experience in controlling their consumption of palatable food does not appear to be due to their greater liking of this food.

We therefore began to consider the possibility that the difficulties of restrained eaters in resisting palatable food could be due to the way in which they cognitively represent palatable food items. In line with the work on delay of gratification of Mischel and his colleagues (e.g., Metcalfe \& Mischel, 1999; Mischel \& Ayduk, 2004; Mischel, Shoda, \& Rodriguez, 1989), we assumed that restrained eaters are more likely than unrestrained eaters to access "hot" representations of palatable food stimuli, reflecting the arousing, consummatory features of the food (i.e., its taste and texture), whereas unrestrained eaters use "cool," informational representations of food items. As Mischel's work on delay of gratification has amply demonstrated, a focus on the "hot" features of food stimuli, makes delay of gratification much more difficult (e.g., Mischel \& Moore, 1973).

A study by Papies et al., 2007 provided support for this interpretation. Papies et al., demonstrated that exposure to palatable food was more likely to stimulate spontaneous thoughts about the "hot" features of this food in restrained than in unrestrained eaters. Using a probe recognition task (McKoon \& Ratcliff, 1986), Papies et al., exposed research participants to a number of behavior descriptions that were immediately followed by a probe word. Participants were asked to respond to the probe word as quickly and as accurately as possible by indicating whether it had been part of the preceding sentence. In the critical trials, the probe word was implied in the preceding sentence without being explicitly mentioned. Reading these sentences should increase the accessibility of the implied concept and this should interfere with the correct response (i.e., No). The critical trials in the study of Papies et al., were sentences that described the consumption of palatable food items. Consistent with the assumption that exposure to cues symbolizing or signaling palatable food items triggers spontaneous "hot" representation of the food items and of the anticipatory pleasure of eating enjoyment in restrained but not in unrestrained eaters, restrained eaters were significantly slower in deciding that words reflecting eating-enjoyment (e.g., tasty, palatable) were not part of critical sentences than were unrestrained eaters. No such differences occurred in the control conditions. A second experiment demonstrated 
that this effect only occurs with words reflecting palatable but not with unpalatable food. Consistent with the assumption that restrained eaters are more likely than unrestrained eaters to think of food in terms of its consummatory "hot" features the presence of palatable food has been found to bias attention to these food items (Papies, Stroebe, \& Aarts, under review), to stimulate more salivary production (Brunstrom, Yates, \& Witcomb, 2004; Tepper, 1992) and to cause a stronger desire to eat this food in restrained than in unrestrained eaters (Fedoroff et al., 1997).

\section{Recapitulation and preview}

According to our goal conflict model, eating behavior of restrained (but not unrestrained) eaters is dominated by a conflict between two incompatible goals, namely the goals of eating enjoyment and weight control. The research reported in this article was designed to test two central assumptions derived from this conceptualization. First, if, as our model assumes, restrained (but not unrestrained) eaters have a conflict between two incompatible goals (the goal of eating enjoyment and weight control), then the attitude of restrained eaters towards palatable food should be characterized by a high degree of ambivalence. They love good food for its taste, but, at the same time, they fear it because of its calories. This assumption will be tested in Study 1.

Our model further postulates that the over-responsiveness of restrained eaters to cues signaling or symbolizing palatable food results from the fact that exposure to these cues triggers the goal of eating palatable food in restrained but not unrestrained eaters. Due to the incompatibility between eating enjoyment and eating control, such an increase in the accessibility of the eating enjoyment goal will result in the inhibition of the mental representation of eating control. We already discussed evidence that restrained eaters are more likely to react with anticipatory eating enjoyment to cues signaling palatable food (Papies et al., 2007) and that priming eating enjoyment results in overeating in restrained but not unrestrained eaters (Fedoroff et al., 1997, Fedoroff, Polivy, \& Herman, 2003). However, there is no evidence yet for the cognitive processes assumed to mediate these effects. Studies 2 and 3 will therefore test the hypothesis that priming the goal of eating enjoyment will inhibit the accessibility of eating control thoughts in restrained a but not unrestrained eaters.

\section{Study 1}

According to the Goal Conflict Model of Eating, the attitude of restrained eaters towards palatable food is characterized by a high degree of ambivalence. Ambivalence can be defined as a psychological state in which a person holds mixed feeling (positive and negative) towards some psychological object (Conner \& Sparks, 2002). Restrained eaters are ambivalent towards palatable food because on the one hand, they like it, but on the other hand, because of their chronic dieting and because it contains calories, they dislike it. Thus, their heart tells them to approach it, but their mind urges them to avoid it. They experience a goal conflict. To test this assumption Study 1 assessed both experienced and structural ambivalence towards eating and related these two measures to eating restrained.

\section{Method}

\section{Participants}

116 female students of Utrecht University received a small fee for participation. The questionnaire sessions were computerized.

\section{Measures}

Experienced ambivalence towards eating $(\alpha=.93)$ was assessed with a self-constructed scale consisting of twelve items (e.g., "I would enjoy tasty food more, if it would not contain so many calories"; "A good meal tastes better, if you forget that it makes you gain weight"). Respondents had to indicate the extent to which these items applied to them on a 7-point scale, ranging from "not at all" to "very much".

Structural ambivalence was assessed with the splitsemantic differential procedure suggested by Kaplan (1972). Respondents are supplied with two uni-polar scales. On the first scale, they were requested to evaluate only the positive aspects of tasty food, ignoring the negative qualities. With the second scale, they were asked to rate all the negative aspects of tasty food, disregarding any positive qualities. The degree of ambivalence was computed with a formula suggested by Griffin $[(\mathrm{P}+\mathrm{N}) / 2-|\mathrm{P}-\mathrm{N}|]$; Thompson, Zanna, and Griffin, 1995. High scores indicate greater ambivalence.

Restrained eating was assessed with a Dutch translation (Jansen, Oosterlaan, Merckelbach, \& Hout, 1988) of the Restraint Scale (Herman \& Polivy, 1980). The Restraint Scale assesses two correlated constructs: Concern for Dieting (CD) and Weight Fluctuations (WF). Typical items of the CD scale are "How conscious are you of what you're eating?" or "Do you have feelings of guilt after overeating?". Examples of items of the WF scale are "What is your maximum weight gain within a week?" or "In a typical week, how much does your weight fluctuate?". The Cronbach $\alpha$ was .83 for the (total) Restraint Scale, .80 for CD and .79 for WF.

\section{Results and discussion}

Table 1 presents the inter-correlations between the various measures. With a correlation of .46 , the magnitude of the relationship between experienced and structural ambivalence is typical for the correlations that have been observed between these types of measures in previous research (Jonas, Broemer, \& Diehl, 2000). It is interesting to note that ambivalence is exclusively determined by the negative aspects of palatable food. There is no correlation 
Table 1

Correlations between restrained eating and the two measures of ambivalence

\begin{tabular}{|c|c|c|c|c|c|c|c|c|}
\hline & & 1 & 2 & 3 & 4 & 5 & 6 & 7 \\
\hline 1. & Experienced Ambivalence & & - & & & & & \\
\hline 2. & Structural ambivalence & $.46^{\mathrm{a}}$ & - & & & & & \\
\hline 3. & Food positive & -.12 & -.02 & - & & & & \\
\hline 4. & Food negative & $.55^{\mathrm{a}}$ & $.83^{\mathrm{a}}$ & -.09 & - & & & \\
\hline 5. & Restraint total & $.56^{\mathrm{a}}$ & $.35^{\mathrm{a}}$ & -.05 & $.52^{\mathrm{a}}$ & - & & \\
\hline 6. & Restraint (concern for dieting) & $.65^{\mathrm{a}}$ & $.34^{\mathrm{a}}$ & -.11 & $.53^{\mathrm{a}}$ & $.91^{\mathrm{a}}$ & - & \\
\hline 7. & Restraint (weight fluctuation) & $.26^{\mathrm{a}}$ & $.27^{\mathrm{a}}$ & .05 & $.34^{\mathrm{a}}$ & $.81^{\mathrm{a}}$ & $.50^{\mathrm{a}}$ & - \\
\hline
\end{tabular}

${ }^{\text {a }}$ Correlations significant at the .01 level (two-tailed).

between the positive aspects of palatable food and either experienced or structural ambivalence.

Both measures of ambivalence are significantly correlated with the total RS-scale as well as the two subscales of RS (CD and WF). This indicates that restrained eaters are characterized by a conflict between the goal of enjoying palatable food and the goal of weight control. They are individuals, who "would enjoy tasty food more, if it would not contain so many calories" and who are highly polarized in their evaluation both of the positive and the negative aspects of food. Again, it is the negative aspects of palatable food that are most closely associated with eating restraint. The positive aspects are uncorrelated with the RS-scale as well as the two subscales. This pattern is consistent with the results of studies on attitude towards palatable food described earlier that found eating restraint unrelated to attitudes (Mensink, 2005; Roefs et al., 2005). Thus, both restrained and unrestrained eaters like tasty food, but restrained eaters worry about calories and therefore feel highly ambivalent towards eating tasty food.

Finally, both measures of ambivalence are more highly correlated with the CD- than the WF-scale. To investigate this issue further, we conducted two multiple regression analyses with the CD- and WF-scale as predictors and the two measures of ambivalence as criterion. For both experienced and structural ambivalence only the association with the CD-scale was significant (Table 2). This is not surprising, because only the $\mathrm{CD}$-scale is likely to reflect directly one of the two goals that form part of the goal conflict, namely the goal of weight control. In view of this pattern as well as the relatively low correlation between these two subscales, we decided to use only the CD-scale in the further testing of our Goal Conflict Model. This choice is also consistent with the suggestions of several researchers

Table 2

Association between $\mathrm{CD} / \mathrm{WF}$ scales and ambivalence: multiple regression results

\begin{tabular}{lrrrr}
\hline & $\beta$ & $d f$ & \multicolumn{1}{c}{$t$} & $P$ \\
\hline Experienced ambivalence & & & & \\
Concern for dieting & .694 & 1,114 & 8.471 & .001 \\
Weight fluctuations & -.089 & 1,114 & -1.084 & .281 \\
Structural ambivalence & & & & \\
Concern for dieting & .267 & 1,114 & 2.638 & .01 \\
Weight fluctuations & .135 & 1,114 & 1.335 & .184 \\
\hline
\end{tabular}

that of the two subscales, the CD subscale is more predictive of eating restraint (e.g., Blanchard \& Frost, 1983; Strien, Breteler, \& Ouwens, 2002; Wardle, 1986).

\section{Study 2}

Study 2 was designed to test the central hypothesis of our goal conflict model, namely that a stimulation of eating enjoyment would result in a inhibition of thoughts about eating control in restrained but not in unrestrained eaters. We used subliminal priming procedures for the stimulation of eating enjoyment to assure that our participants remain unaware of the priming of this goal, thus preventing strategic control over their eating control thoughts. The accessibility of concepts reflecting eating control was measured with a lexical decision task (Bargh \& Chartrand, 2000; Dijksterhuis, Aarts, \& Smith, 2005). Following previous work of this kind, it was assumed that the time taken to recognize the behavioral concepts in this task would reflect relative accessibility of representations of eating control behavior (e.g., Aarts \& Dijksterhuis, 2000, 2003; Neely, 1991). As Veling and van Knippenberg (2004) have recently argued, delayed response latency is the most direct indicator of inhibition.

\section{Method}

\section{Participants}

Eighty-three female undergraduate students at Utrecht University took part in this experiment on "language and decision making" and were paid a small fee for their participation. The study used a 2 (Concern for Dieting: High/ Low) $\times 2$ (Prime: Eating Enjoyment/Neutral) between participants factorial design.

\section{Procedure}

When participants arrived at the laboratory, they were led into individual cubicles and seated in front of a computer monitor. The lexical decision task contained 60 trials. In each trial, participants were primed subliminally. The priming stimulus was preceded by a premask (a string of x's) that remained for $500 \mathrm{~ms}$. Then the prime was presented for $23 \mathrm{~ms}$, followed for $500 \mathrm{~ms}$ by a postmask (a row of x's). Thus, proper pre- and postmasking rendered the very short presentation time of the prime impossible to 
detect consciously. After that the target word appeared to which participants had to react, by deciding as quickly as possible (by pressing a "yes" or "no" key) whether the stimulus represented a word or a non-word letter string. Thus, this procedure used a subliminal prime and relatively short stimulus onset asynchrony (SOA) of $523 \mathrm{~ms}$ to prevent strategic processes upon exposure of eating enjoyment, e.g., searching memory for diet related words. Participants received two practice trials before the actual task began. Five of these sixty trials were critical trials, in which the dependent variable was being assessed, namely the mean reaction time. The five targets in these trials represented the concept of dieting. The following words were used: slim (slank), weight-loss (afvallen), weight (gewicht), diet (diët), and dieting (lijnen). Whereas participants in the experimental condition were primed with five words reflecting the concept of eating enjoyment [tasty (lekker), appetizing (smakelijk) for snoepen, smikkelen, smullen, no English equivalent], respondents in the control condition were primed with neutral words (e.g., neither, over).

The remainder of the trials was similar in both conditions. In these trials, the primes were always neutral and the targets were either neutral words or non-words. The neutral words used in these trials were different from the ones in the critical trials of the control condition. All 60 trials were presented in random order and the pairing of primes and targets was fixed, but randomly selected by the experimenter.

Then, after an unrelated filler task, participants filled out the Concern for Dieting subscale of the Restraint Scale (Herman \& Polivy, 1980). This order was decided upon because exposure to this scale before the lexical decision task would have primed respondents with regard to dieting. Importantly, this measure was evenly distributed across the prime and control condition, $F<1$, indicating that participants' reports on the scale were not affected by the prime manipulation. Accordingly, based on the findings of Study 1 , we used the Concern for Dieting subscale as our measure of eating restraint.

\section{Results}

We predicted an ordinal interaction between eating restraint and priming condition. Since the interaction pattern in a standard interaction cross product assume bilinearity, we used bandwidth regression as informal diagnostic to assess whether our interaction departed from linearity (Blanton \& Jaccard, 2006). Due to the small sample size, we were only able to create four strata that grouped together individuals with similar $z$-scores. For each group separately, we regressed prime on reaction times and recorded the value of the regression coefficient. Table 3 (top panel) presents the values for each group as well as the mean $z$-scores for that group. The interaction pattern in a standard interaction cross product assumes that the regression coefficient for prime will increase by roughly equivalent steps with each increase in eating
Table 3

Bandwidth regression diagnostic for Studies 2 and 3

\begin{tabular}{llcc}
\hline & & $\begin{array}{l}\text { Restraint } \\
z \text {-score }\end{array}$ & $\begin{array}{l}\text { Slope of prime on } \\
\text { reaction times }\end{array}$ \\
\hline Study 1 & & \\
Group 1 & $(N=19)$ & -1.29 & -.06 \\
Group 2 & $(N=24)$ & -.28 & .07 \\
Group 3 & $(N=16)$ & .45 & .37 \\
Group 4 & $(N=26)$ & 1.51 & .30 \\
Study 2 & & & .11 \\
Group 1 & $(N=28)$ & -.97 & .36 \\
Group 2 & $(N=18)$ & -.25 & .38 \\
Group 3 & $(N=16)$ & .55 & -.13 \\
Group 4 & $(N=14)$ & 1.63 & \\
\hline
\end{tabular}

restraint. As we can see from Table 2, this is not the case. The regression coefficients for slope increase steeply between Groups 2 and 3 and then level off, suggesting a ceiling effect. This pattern suggests a non linear interaction. We therefore decided to use median split instead of regression and categorized participants into two groups on the basis of a median split $(M E D=6)$ : unrestrained versus restrained eaters.

All analyses were based only on the correct responses. Overall, $1.1 \%$ of the responses were incorrect (subjects pressed "no" instead of "yes"). Restrained and unrestrained eaters did not differ in accuracy, $F(1,79)=.00$, $n s$, and there was no main effect of condition, $F(1,79)=.02, n s$, and no interaction between restraint and condition, $F(1,79)=.15$, ns. On each diet target, reaction times lower than $300 \mathrm{~ms}$ and higher than $3000 \mathrm{~ms}$ were excluded to lessen the influence of outliers.

Fig. 1 presents the mean reaction time to the five diet targets of unrestrained and restrained eaters, who have either been primed with a neutral or an eating enjoyment prime. A 2 (restrained status: unrestrained vs. restrained) by 2 (prime: neutral vs. eating enjoyment) ANOVA was performed on these mean reaction times. This analysis yielded no main effect of restraint, $F(1,79)=.11, n s$, or of prime, $F(1,79)=1.16 n s$. However, the interaction

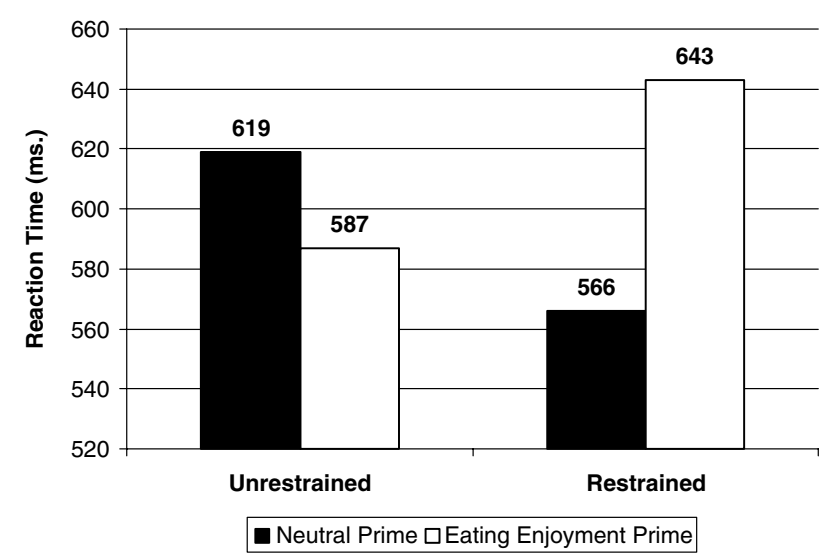

Fig. 1. Mean reaction time to diet targets of restrained and unrestrained eaters primed with eating enjoyment (category) or neutral words. 
between restraint and condition was significant, $F(1,79)=6.85, p=.011$. A test of the simple effects revealed that the mean reaction times between the condition with neutral primes and with the "eating enjoyment" primes did not differ significantly for unrestrained eaters, $F(1,80)=1.00$, ns. For restrained eaters, however, the mean reaction time in the condition with the "eating enjoyment" primes was significantly higher than in the condition with neutral primes, $F(1,79)=8.46, p=.005$.

Interestingly, restrained eaters in the (neutral-prime) control condition appear to have shorter recognition times for diet-related words than the unrestrained eaters in this condition $F(1,79)=4.11, p=.05$. Consistent with our model, these findings suggest that individuals with a high concern for dieting will activate dieting concepts much more frequently than individuals for whom dieting is not an issue, and hence dieting concepts should have a higher chronic accessibility for restrained than for unrestrained eaters.

\section{Discussion}

The findings of this study support the prediction derived from the Goal Conflict Model of Eating that subliminally priming the concept of eating enjoyment significantly increased the time that participants with high scores on the Concern for Dieting subscale of the Restraint Scale (restrained eaters) needed to recognize diet-related words. The same manipulation had no significant impact on respondents who had scored low on the Concern for Dieting subscale (unrestrained eaters). We have to conclude that increasing the accessibility of thoughts about eating enjoyment through subliminal priming decreased the accessibility of dieting concepts in restrained but not in unrestrained eaters. ${ }^{1}$

One might argue that, in the present study, we primed the eating enjoyment goal directly, using adjectives such as "tasty" or "appetizing". In everyday life, however, these thoughts would be stimulated less directly by exposure to one's favorite food. Thus, we assume that exposure to the word "French Fries" on a menu presents palatable food and will stimulate in a restrained eater the goal of eating (i.e., eating enjoyment). If this reasoning were correct, one should be able to replicate the pattern revealed in Study 2 by priming eating enjoyment indirectly, using words for favorite food items as primes rather than directly using words referring to the tastiness of these food items.

\footnotetext{
${ }^{1}$ One reviewer offered two plausible alternative explanations for these findings: (1) restrained eaters might have been more distracted by thinking about tasty food and hence show slower recovery times (2) they might have experienced more positive mood and therefore processed the stimuli more slowly. However, Papies, Stroebe and Aarts (submitted for publication) found no difference in the response times of unrestrained eaters in a lexical decision task using words referring to palatable food, to non palatable and to non food items. The failure for Papies et al., to find either main effects or interactions in this study renders these alternative interpretations of our Study 2 implausible.
}

\section{Study 3}

To test whether exposure to words describing favorite food items will stimulate the goal of eating enjoyment in the same way as words that directly refer to the enjoyment expected from eating this food, Study 3 used two types of primes, namely words directly referring to the eating experience (category words), or words referring to favorite food items (object words), with the last factor as a within participants factor.

\section{Method}

\section{Participants}

Seventy-six female students from Utrecht University were paid a small fee for participation in this experiment. Participants did not know in advance that this study concerned eating behavior. The design of the study was a 2 (restrained status: unrestrained vs. restrained) by 2 (prime: neutral vs. eating enjoyment) by (type of prime-word: category vs. object words), with type of prime as a within factor.

\section{Procedure}

The procedure was practically identical to that used in Study 2. The lexical decision task contained 120 trials (2 blocks of the same 60 trials) and participants were primed subliminally before each trial. The duration of the pre- and post-masking as well as the exposure time for the primes remained the same as in Study 2. However, in this Study, ten trials formed the critical trials: Five of these used the direct eating enjoyment primes of Study 2 and five used words referring to favorite food items. The same target words (reflecting dieting) as Study 2 were used in these critical trials.

Participants in the experimental conditions were either primed with the five category words reflecting eating enjoyment used in Study 2 or with five object words referring to tasty food items (crisps, French fries, chocolate, pancakes, ice-cream). In the control conditions, participants were either primed with the five neutral words used in Study 1 (e.g., neither, over, immediately) or with five neutral object words (airplane, bus, train, car, bike). The remaining trials were identical in both conditions. In these trials the primes were always neutral and the targets were either neutral words or non-words. The 120 trials were divided into two blocks. The first 60 trials were presented in random order and pairing of primes and targets was assigned randomly by computer. After subjects performed the lexical decision task they were given a one minute break. Subsequently they had to perform the second block of trials. Thus, in the present study the averaged response time across the 10 category and objects words comprised the dependent variable of interest.

After the lexical decision task, respondents were asked to fill out the Concern for Dieting subscale of the Restraint Scale (Herman \& Polivy, 1980). As in Study 2, participants' 
reports on the scale were not affected by the prime manipulation, $F<1$.

\section{Results}

As in Study 2, we first performed a bandwidth regression as informal diagnostic to assess whether our interaction departed from bilinearity (Blanton \& Jaccard, 2006). Again, we were only able to create four strata that grouped together individuals with similar $z$-scores due to the small sample size. For each group separately, we regressed prime on reaction times and noted the value of the regression coefficient. The bottom panel of Table 3 presents the values for each group as well as the mean z-scores for that group. This time there was a glaring departure for the slope for Group 4 relative to Group 3, again indicating a ceiling effect. We therefore decided to use median split instead of regression. Participants were classified as unrestrained or restrained eaters by median split on the Concern for Dieting subscale $(\mathrm{MED}=4)$.

All analyses were based only on correct responses. Overall, $1.4 \%$ of the responses were incorrect (subjects pressed "no" instead of "yes"). Restrained and unrestrained eaters did not differ in accuracy, $F(1,72)=2.57, n s$, and there was no main effect of condition, $F(1,72)=.1, n s$, and no interaction between restraint and condition, $F(1,72)=.1$, ns. On each diet target, reaction times below 300 and $3000 \mathrm{~ms}$ were excluded.

A 2 (restraint status: unrestrained vs. restrained) by 2 (prime: neutral vs. eating enjoyment) ANOVA with type of prime (category vs. object) as within subjects factor was performed on mean reaction times to the diet targets. This analysis yielded no main effects of restraint, $F(1,72)=.13$, ns, prime, $F(1,72)=1.10$, ns, or type of prime word, $F(1,72)=.14, n s$. There were also no twoway interactions between prime and type of prime word, $F(1,72)=.23, n s$, or between restraint and type of prime word, $F(1,72)=.10, n s$, and no significant three-way interaction, $F(1,72)=.56$, ns. However, as predicted, the two-way interaction between restraint and prime was significant, $F(1,72)=5.73, p=.019$.

Because there were no effects for type of prime word used, reaction time were collapsed across types of prime words (Fig. 2). A test on the simple effect on these collapsed data revealed that the difference between the neutral prime and the eating enjoyment prime conditions was only significant for restrained, $F(1,73)=6.68, p=.012$, but not for unrestrained eaters, $F(1,73)=.78, n s$.

Furthermore, replicating the pattern obtained in Study 2 , restrained eaters in the (neutral-prime) control condition appear to have shorter recognition times for diet-related words than the unrestrained eaters in this condition, although this difference failed to reach significance, $F(1,73)=1.98, p=.16$.

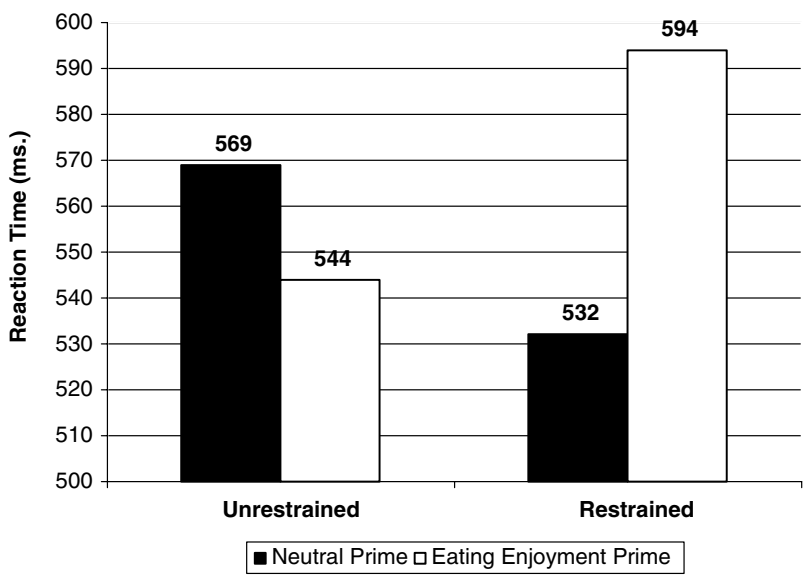

Fig. 2. Mean reaction time to diet targets of restrained and unrestrained eaters primed with eating enjoyment (category; object) or neutral words.

\section{Discussion}

The pattern of results of this study replicates and extends the findings of Study 2. As in Study 2, the priming of eating enjoyment significantly increased the time that participants with high scores on the Concern for Dieting subscale of the Restraint scale needed to recognize dietrelated words (Fig. 2). Furthermore, it did not make any difference whether eating enjoyment was primed directly with category words denoting eating enjoyment (e.g., tasty) or more indirectly with object words referring to food items, which these respondents enjoy eating (e.g., chips, ice cream).

Another important aspect of the findings of Study 3 is the replication of the chronic accessibility of the goal of eating control in restrained eaters observed in Study 2. Specifically, in the (neutral prime) control condition, restrained eaters appeared to have shorter recognition times for dietrelated words than did unrestrained eaters. It is this high chronic accessibility of dieting thoughts, combined with the fact that weight control and eating enjoyment are incompatible goals, that makes it necessary for restrained eaters, who (albeit implicitly) want to enjoy their food, to actively suppress thoughts about dieting. And finally, priming eating enjoyment had no significant impact on reaction times of unrestrained eaters.

These findings support the predictions derived from the Goal Conflict Model of Eating that exposure to stimuli likely to prime the goal of eating enjoyment in individuals with a high Concern for Dieting results in an inhibition of the goal of weight control. It does not matter whether the eating enjoyment goal is primed directly using adjectives that reflect eating enjoyment or whether it is primed more indirectly by exposing respondents to words referring to their favorite food. After having been primed with eating enjoyment, these chronic dieters need more time to access dieting related concepts than after having been primed with neutral primes. In contrast, individuals with a low Concern for Dieting are not affected by either prime. 


\section{General discussion}

According to our goal conflict model the problems restrained eaters experience in controlling their food intake are due to a conflict between their goal to enjoy palatable food and their desire to control their weight. In support of the assumption that restrained eaters experience a goal conflict with regard to eating, Study $1 \mathrm{dem}$ onstrated a substantial positive correlation between participants' scores on the Restraint Scale and measures of structural as well as experienced ambivalence towards eating. Since it was mainly the Concern for Dieting subscale that correlated with ambivalence and since the CD scale is likely to reflect one of the two goals that form part of the goal conflict, we decided to use only the CD-scale in testing our second hypothesis.

The goals of eating enjoyment and eating control are incompatible with each other. Even if some restrained eaters may have learnt that they are allowed to enjoy small amounts of appealing food, limiting oneself to eating only small amounts requires the weight control goal. Restrained eaters therefore have to shield the goal of weight control by inhibiting or devaluing the goal of eating enjoyment. Palatable food has a strong positive incentive value for restrained eaters, who, exposed to palatable food items, spontaneously trigger the consummatory features of such food and the enjoyment they would derive from eating it. Continual stimulation of the goal of eating enjoyment through priming is likely to increase its accessibility to the extent that it interferes with the goal of weight control and finally produces inhibited access to the representation of the eating control goal. This prediction was supported by the results of Studies 2 and 3 .

These finding go some way towards explaining the difficulties restrained eaters experience in keeping to their diets. The eating situation is often structured in ways that make eating enjoyment cues particularly salient at the beginning of a meal. One may be hungry and there may be a delicious smell of food. When eating in a restaurant, one also has to choose from a menu that may offer a wide range of one's favorite food. With these cues, the goal of eating enjoyment is likely to become dominant in restrained eaters. Since it is difficult to enjoy one's food while thinking about one's weight, all plans about dieting and calorie restriction may be momentarily "forgotten." By the time these dieting thoughts are allowed to resurface, a restrained eater might decide to finish the meal with a sweet course, because the diet for the day will have been ruined anyway (Herman \& Polivy, 1984; "what the hell cognitions").

We would like to emphasize that these inhibitory effects are not symmetrical. Restrained eaters are chronic dieters who try to shield their dieting goal by inhibiting thoughts about eating enjoyment. Thus, during the normal state of inhibition, priming the dieting goal would have no impact on the accessibility of eating enjoyment thoughts. However, during states of disinhibition, for example after eating enjoyment had become highly accessible due to repeated exposure to stimuli signaling or symbolizing extremely palatable food, diet primes would result in reestablishing inhibition of the eating enjoyment goals. This has been demonstrated by Papies et al. (under review) in her study of the attentional bias for palatable food among restrained eaters. Papies et al., demonstrated that attentional bias for palatable food items only emerged in restrained eaters, once they had been primed with eating enjoyment, and disappeared, if they were subsequently (subliminally) primed with eating control.

It is important to realize that, in the present set of experiments, the eating enjoyment items were presented subliminally $(23 \mathrm{~ms})$ and the SOA (the time between the exposure to the eating enjoyment items and the recognition of the weight control concepts) was chosen to be relatively short (523 ms). Within these time windows, then, we demonstrated that the facilitation of eating enjoyment is capable of directly inhibiting the concept of weight control. These findings further establish the important point that restrained eaters, who are largely unsuccessful in controlling their weight to the level of their subjective standards (Herman \& Polivy, 1984; Stroebe, 2000, 2002), readily inhibit their weight control goal in order to follow their eating enjoyment goal. This notion coincides with recent research conducted by Fishbach, Friedman, and Kruglanski (2003; Study 4), in which traces of inhibited access to the concept of dieting were established for students who reported to be unsuccessful dieters. In other words, the activation of the goal of eating enjoyment inhibits the weight control goal to more swiftly guide the behavioral output in the direction of taking and eating tasty food (see also, e.g., Anderson \& Spellman, 1995; for demonstrations of enduring episodes of inhibited access to mental representations).

Although our studies demonstrated that priming of eating enjoyment reduces the accessibility of the eating control goal in restrained eaters, we did not assess whether this type of priming would also result in overeating. However, empirical support for this assumption comes from studies reviewed earlier that demonstrated that priming of eating enjoyment results in overeating in restrained but not unrestrained eaters (e.g., Fedoroff et al., 1997, 2003; Jansen \& van den Hout, 1991). In line with our findings, we would argue that exposure to, for example, the smell of freshly baked pizza increases the accessibility of the eating enjoyment goal in restrained eaters, resulting in a direct inhibition of the goal of eating control. Having momentarily forgotten their dieting plans, restrained eaters then tuck in and enjoy the pizza (Fedoroff et al., 1997). That priming food thoughts can also induce overeating in obese individuals had already been demonstrated much earlier by Tom and Rucker (1975), who had obese and normal weight respondents rate the appeal of 35 slides depicting either palatable meals or scenic areas of the USA before they were asked to taste and evaluate different types of crackers. Obese participants ate significantly more crackers after having been exposed to food slides (i.e., after having been primed with food cues) than after seeing country-side 
scenes, whereas type of slide made no different for normal weight respondents.

With tempting food all around us, eating enjoyment will be continually primed and it will take a major effort for restrained eaters to fight against the inhibition of their dieting thoughts. Our goal conflict theory suggests several strategies restrained eaters might employ to prevent the breakdown of eating control. First, their problem in resisting palatable food appears to be aggravated by their "hot" consummatory representations of such food, and their difficulty in disengaging from these thoughts. Extrapolating from the research of Mischel and colleagues (e.g., Mischel et al., 1989) on delay of gratification, distraction or abstraction might lessen the temptation. Thus, restrained eaters should either try to distract themselves by thinking about issues unrelated to eating, or they could try to focus on the "cool" symbolic aspects of food stimuli (see also Millar \& Tesser, 1989). Another strategy would be to think about how one would feel afterwards, if one would break one's diet. Research on condom use has shown that anticipated regret about having unsafe sex increased condom use (Richard, van der Pligt, \& de Vries, 1996).

Whereas these strategies rely on conscious effort and self-control, restrained eaters could also try to use automatic processes to benefit self-regulation. According to our goal conflict theory, cues that trigger dieting thoughts should reestablish the dieting goal in restrained eaters, whose resolve has been weakened by "hot" representations of palatable food items and the pleasant anticipation of eating enjoyment. In support of this assumption, Papies et al. (under review) demonstrated that subliminally priming restrained eaters with dieting primes could undo the effect of eating enjoyment primes. This would suggest that planting dieting cues in strategic locations of restrained eaters' environment could help to counteract the influence of food temptations. If successful, such repeated associations of eating enjoyment and dieting goals might even lead to a state where food temptations would directly trigger the dieting goal (e.g., Fishbach et al., 2003).

\section{Acknowledgments}

The empirical research reported in this paper was funded by a grant form the Research Institute of Psychology and Health to W. Stroebe and H. Schut. The contribution of Henk Aarts to the work reported in this paper was supported by a grant from the Netherlands Organization for Scientific Research (VIDI 452-02-047).

\section{References}

Aarts, H., \& Dijksterhuis, A. (2000). Habits as knowledge structures: automaticity in goal-directed behavior. Journal of Personality and Social Psychology, 78, 53-63.

Aarts, H., \& Dijksterhuis, A. (2003). The silence of the library: environment, situational norm and social behavior. Journal of Personality and Social Psychology, 84, 18-28.
Anderson, M. C., \& Spellman, B. A. (1995). On the status of inhibitory mechanisms in cognition: memory retrieval as a model case. Psychological Review, 102, 68-100.

Bargh, J. A., \& Chartrand, T. L. (2000). Studying the mind in the middle: a practical guide to priming and automaticity research. In H. Reis \& C. Judd (Eds.), Handbook of research methods in social psychology. New York: Cambridge University Press.

Baucom, D. H., \& Aiken, P. A. (1981). Effect of depressed mood on eating among obese and nonobese dieting and nondieting persons. Journal of Personality and Social Psychology, 41, 577-585.

Blanchard, F. A., \& Frost, R. O. (1983). Two factors of restraint: Concern for dieting and weight fluctuation. Behaviour Research and Therapy, 21, 259-267.

Blanton, H., \& Jaccard, J. (2006). Tests of multiplicative models in psychology: a case study using the unified theory of implicit attitudes, stereotypes, self-esteem, and self-concept. Psychological Review, 113, $155-169$.

Bodenhausen, G. V., \& Macrae, C. N. (1998). Stereotype activation and inhibition. In R. S. Wyer (Ed.). Advances in social cognition (Vol. 11, pp. 1-52). Mahwah, NJ: Erlbaum.

Bolles, R. C. (1990). A functionalistic approach to feeding. In E. D. Cipaldi \& T. L. Powley (Eds.), Taste, experience, and feeding (pp. 1-13). Washington, DC: American Psychological Association.

Bouchard, C. P., Pérusse, L., Rice, T., \& Rao, D. C. (1998). The genetics of human obesity. In G. A. Bray, C. Bouchard, \& W. P. T. James (Eds.), Handbook of obesity (pp. 157-190). New York: Dekker.

Bruch, H. (1961). The transformation of oral impulses in eating disorders: a conceptual approach. Psychiatric Quarterly, 35, 458-481.

Brunstrom, J. M., Yates, H. M., \& Witcomb, G. L. (2004). Dietary restraint and heightened reactivity to food. Physiology and Behavior, $81,85-90$

Conner, M., \& Sparks, P. (2002). Ambivalence and attitudes. In W. Stroebe \& M. Hewstone (Eds.). European review of social psychology (Vol. 12, pp. 37-70). Chichester: Wiley.

Dijksterhuis, A., Aarts, H., \& Smith, P. K. (2005). The power of the subliminal: subliminal perception and possible applications. In R. R. Hassin, J. S. Uleman, \& J. A. Bargh (Eds.), The new unconscious. New York: Oxford University Press.

Fedoroff, I. C., Polivy, J., \& Herman, C. P. (1997). The effect of preexposure to food cues on the eating behavior of restrained and unrestrained eaters. Appetite, 28, 33-47.

Fedoroff, I. C., Polivy, J., \& Herman, C. P. (2003). The specificity of restrained versus unrestrained eaters' responses to food cues: general desire to eat, or craving for cued food?. Appetite 41, 7-13.

Fishbach, A., Friedman, R. S., \& Kruglanski, A. W. (2003). Leading us not onto temptation: momentary allurements elicit overriding goal activation. Journal of Personality and Social Psychology, 84, 296-309.

Frost, R. O., Goolkasian, G. A., Ely, R. J., \& Blanchard, F. A. (1982). Depression, restraint, and eating behavior. Behaviour Research and Therapy, 20, 113-121.

Goldman, R., Jaffa, M., \& Schachter, S. (1968). Yom Kippur, Air France, dormitory food, and the eating behavior of obese and normal persons. Journal of Personality and Social Psychology, 10, 117-123.

Heatherton, T. E., Herman, C. P., \& Polivy, J. (1991). Effects of physical threat and ego threat on eating. Journal of Personality and Social Psychology, 60, 138-143.

Heatherton, T. F., Striepe, M., \& Wittenberg, L. (1998). Emotional distress and disinhibited eating: the role of self. Personality and Social Psychology Bulletin, 24, 301-313.

Herman, C. P., \& Mack, D. (1975). Restrained and unrestrained eating. Journal of Personality, 43, 647-660.

Herman, C. P., \& Polivy, J. (1980). Restrained eating. In A. J. Stunkard (Ed.), Obesity (pp. 208-225). Philadelphia: Saunders.

Herman, C. P., \& Polivy, J. (1984). A boundary model for the regulation of eating. In J. A. Stunkard \& E. Stellar (Eds.), Eating and its disorders (pp. 141-156). New York: Raven Press.

Herman, C. P., Polivy, J., \& Esses, V. M. (1987). The illusion of counterregulation. Appetite, 9, 161-169. 
Herman, C. P., Polivy, J., Lank, C. N., \& Heatherton, T. F. (1987). Anxiety, hunger and eating behavior. Journal of Abnormal Psychology, 96, 264-269.

Hibscher, J. A., \& Herman, C. P. (1977). Obesity, dieting and the expression of obese characteristics. Journal of Comparative and Physiological Psychology, 91, 374-380.

Jansen, A., \& Hout, van den (1991). On being led into temptation: "Counterregulation" of dieters after smelling a "preload". Addictive Behaviors, 16, 247-253.

Jansen, A., Oosterlaan, J., Merckelbach, H., \& Hout, M. A. van den (1988). Nonregulation of food intake in restrained emotional and external eaters. Journal of Psychopathology and Behavioral Assessment, $10,345-353$.

Jonas, K., Broemer, P., \& Diehl, M. (2000). Attitudinal ambivalence. In W. Stroebe \& M. Hewstone (Eds.). European review of social psychology (Vol. 11, pp. 35-74). Chichester: Wiley.

Kaplan, K. J. (1972). On the ambivalence-indifference problem in attitude theory and measrument A suggested modification of the semantic differential technique. Psychological Bulletin, 77, 361-372.

Kruglanski, A. (1996). Goals as knowledge structures. In P. M. Gollwitzer \& J. A. Bargh (Eds.), The psychology of action (pp. 599-618). New York: Guilford.

McKoon, G., \& Ratcliff, R. (1986). Inferences about predictable events. Journal of Experimental Psychology: Learning, Memory and Cognition, $12,82-91$.

Mensink, W. (2005). Why dieting fails: testing a goal conflict model of eating behavior. Utrecht University: Doctoral Dissertation.

Mensink, W., Stroebe, W., \& Schut, H. (2001). Unpublished data set. The Netherlands: Utrecht University.

Metcalfe, J., \& Mischel, W. (1999). A hot/cool-system analysis of delay of gratification: dynamics of willpower. Psychological Review, 106, 3-19.

Millar, M. G., \& Tesser, A. (1989). The effects of affective-cognitive consistency and thought on the attitude-behavior relation. Journal of Experimental Social Psychology, 25, 189-202.

Mischel, W., \& Ayduk, O. (2004). Willpower in a cognitive-affective processing systemt: the dynamics of delay of gratification. In R. F. Baumeister \& K. D. Vohs (Eds.), Handbook of self-regulation (pp. 99-129). New York: Guilford.

Mischel, W., \& Moore, B. (1973). Effects of attention to symbolically presented rewards on self-control. Journal of Personality and Social Psychology, 28, 172-179.

Mischel, W., Shoda, Y., \& Rodriguez, M. L. (1989). Delay of gratification in children. Science, 244, 933-938.

Neely, J. (1991). Semantic priming effects in visual word recognition: a selective review of current findings and theories. In D. Besner \& G. Humpreys (Eds.), Basic processes in reading: Visual word recognition (pp. 264-336). Hillsdale, NJ: Erlbaum.

Nisbett, R. E. (1968). Taste, deprivation, and weight determinants of eating behavior. Journal of Personality and Social Psychology, 10, 107-116.

Nisbett, R. E. (1972). Hunger, obesity, and the ventromedial hypothalamus. Psychological Review, 79, 433-453.

Norman, D. A., \& Shallice, T. (1986). Attention and action: Willed and automatic control of behavior. In R. J. Davidson, G. E. Schwartz, \& D. Shapiro (Eds.). Consciousness and self-regulation: Advances in research and theory (Vol. 4, pp. 1-18). New York: Plenum.
Papies, E., Stroebe, W., \& Aarts, H. (2007). Pleasure in the mind: restrained eating and spontaneous hedonic thoughts about food. Journal of Experimental Social Psychology, 43(5), 810-817.

Papies, E., Stroebe, W., \& Aarts, H. (under review). The allure of forbidden food: on the role of attention in self-regulation.

Pinel, J. P. J., Assanand, S., \& Lehman, D. R. (2000). Hunger, eating, and ill health. American Psychologist, 55, 1105-1116.

Polivy, J., Herman, C. P., \& McFarlane, T. (1994). Effects of anxiety on eating: Does palatibility moderate distress-induced overeating in dieters? Journal of Abnormal Psychology, 103, 505-510.

Richard, R., van der Pligt, J., \& de Vries, N. K. (1996). Anticipated regret and time perspective: changing sexual risk-taking behavior. Journal of Behavioral Decision Making, 9, 185-199.

Rodin, J. (1981). Current status of the internal-external hypothesis for obesity. American Psychologist, 36, 361-372.

Roefs, A., Herman, C. P., MacLead, C. M., Smulders, F. T. Y., \& Jansen, A. (2005). At first sight: how do restrained eaters evaluate high-fat palatable foods? Appetite, 44, 103-114.

Ruderman, A. J. (1986). Dietary restrain: a theoretical and empirical review. Psychological Bulletin, 99, 247-262.

Schachter, S. (1971). Emotion obesity and crime. New York: Academic Press.

Schachter, S., \& Gross, L. P. (1968). Manipulated time and eating behavior. Journal of Personality and Social Psychology, 10, 98-106.

Schachter, S., Goldman, R., \& Gordon, A. (1968). Effects of fear, food deprivation, and obesity on eating. Journal of Personality and Social Psychology, 10, 91-97.

Shah, J. Y., \& Kruglanski, A. W. (2002). Priming against your will: How accessible alternatives affect goal pursuit. Journal of Experimental Social Psychology, 38, 384-396.

Shah, J. Y., Friedman, R., \& Kruglanski, A. W. (2002). Forgetting all else: On the antecedents and consequences of goal shielding. Journal of Personality and Social Psychology, 83, 1261-1280.

Strien, T. van, Breteler, M. H. M., \& Ouwens, M. A. (2002). Restraint scale, its sub-scales concern for dieting and weight fluctuation. Personality and Individual Differences, 33, 791-802.

Stroebe, W. (2000). Social psychology and health (2nd ed.). Buckingham: Open University Press.

Stroebe, W. (2002). Übergewicht als Schicksal? Die kognitive Steuerung des Essverhaltens. Psychologische Rundschau, 53, 14-22.

Tepper, B. J. (1992). Dietary restraint and responsiveness to sensory-based food cues as measured by cephalic phase salivation and sensory specific satiety. Physiology and Behavior, 52, 305-311.

Thompson, M. M., Zanna, M. P., \& Griffin, D. W. (1995). Let's not be indifferent about (attitudinal) ambivalence. In R. E. Petty \& J. A. Krosnick (Eds.), Attitude strength: Antecedents and consequences (pp. 361-386). Mahwah: Erlbaum.

Tom, G., \& Rucker, M. (1975). Fat, full, and happy: effects of food deprivation, external cues, and obesity on preference ratings, consumption, and buying intention. Journal of Personality and Social Psychology, 32, 761-767.

Veling, H., \& van Knippenberg, A. (2004). Remembering can cause inhibition: retrieval-induced inhibition as cue independent effect. Journal of Experimental Psychology: Learning, Memory, and Cognition, 30, 315-318.

Wardle, J. (1986). The assessment of restrained eating. Behaviour Research and Therapy, 24, 213-215.

World Health Organization (2000). Obesity: preventing and managing he global epidemic. Geneva: WHO technical report series, 894. 